\title{
Cartografia dos Centros de Convivência: a produção de encontros e de redes*
}

\section{Mapping of Community Centers: production of meetings and networks}

\author{
Sabrina Helena Ferigato ${ }^{1}$, Sérgio Resende Carvalho ${ }^{2}$, Ricardo Rodrigues Teixeira ${ }^{3}$
}

http://dx.doi.org/10.11606/issn.2238-6149.v27i1p12-20

Ferigato SH, Carvalho SR, Teixeira RR. Cartografia dos Centros de Convivência: a produção de encontros e de redes. Rev Ter Ocup Univ São Paulo. 2016 jan.-abr.;27(1):12-20.

RESUMO: O presente estudo tem como objeto a produção dos Centros de Convivência (CECOs) na rede intersetorial, tendo o município de Campinas como campo empírico. O objetivo principal do estudo foi identificar, dar visibilidade e analisar a produção dos Centros de Convivência, a partir de uma abordagem qualitativa e do método da cartografia. Adotou como referência teórica a Filosofia da Diferença e os pressupostos da Atenção Psicossocial. Dos resultados se destacou a produção de encontros, como aspecto central da produção dos CECOs: encontros na diferença, o encontro entre usuários com heterogeneidade etária, de gênero e de diagnóstico; o encontro entre profissionais e usuários; o encontro entre diferentes disciplinas, setores e saberes; o encontro com diferentes atividades e o encontro com a cidade.

DESCRITORES: Centros comunitários de saúde; Redes comunitárias; Ação intersetorial.
Ferigato SH, Carvalho SR, Teixeira RR. Mapping of Community Centers: production of meetings and networks. Rev Ter Ocup Univ São Paulo. 2016 Jan.-Apr.;27(1):12-20.

ABSTRACT: This study has as its object the production of Community Centers (CECOs) in the intersectoral network, and has the city of Campinas as empirical field. The main objective was to identify, give visibility, and analyze the creation of Community Centers from a qualitative approach and mapping method. We adopted the Philosophy of Difference and the premises of Psychosocial Care as theoretical reference. From the results, the production of meetings stood out as the central aspect of creation of CECOs: meetings in the difference, between users with diverse age, gender, and diagnosis; meetings between professionals and users; meetings between different disciplines, sectors, and knowledge; meetings with different activities and meetings with the city.

KEYWORDS: Community health centers; Community networks; Intersectoral action.

\footnotetext{
* Esse artigo é resultado da pesquisa de doutorado ${ }^{1}$ intitulada "Cartografia dos Centros de Convivência de Campinas: produzindo redes de encontros", realizada no Departamento de Saúde Coletiva da Unicamp por Sabrina Ferigato sob orientação de Sérgio Resende Carvalho e colaborações de Ricardo Rodrigues Teixeira.

1. Terapeuta ocupacional, professora doutora adjunta do Departamento de Terapia Ocupacional da Universidade Federal de São Carlos e professora colaboradora do Programa de Pós-graduação em Saúde Coletiva da Unicamp.

2. Médico sanitarista, professor doutor Associado do Departamento de Saúde Coletiva da Faculdade de Ciências Médicas da UNICAMP. 3. Médico sanitarista, professor Doutor do Departamento de Medicina Preventiva da Faculdade de Medicina da Universidade de São Paulo. Endereço para correspondência: Departamento de Terapia Ocupacional/UFSCar. Rod. Washington Luis, km 235. São Carlos, SP. CEP: 1365-905. E-mail: sabrinaferigato@gmail.com
} 


\section{INTRODUÇÃO}

$\mathrm{O}$ $\mathrm{s}$ Centros de Convivência são dispositivos públicos que compõe a rede intersetorial, que oferecem espaços de sociabilidade, produção cultural e intervenção na cidade. São abertos à comunidade e especialmente às pessoas em situação de vulnerabilidade ou exclusão social ${ }^{2,3}$. Por meio da construção de espaços de convívio, os Centros de Convivência promovem espaços de articulação com a vida cotidiana e com o território por meio de ações de diferentes setores como a Saúde, a Assistência Social, a Educação e a Cultura.

Essa pesquisa buscou cartografar a produção dos CECOs a partir da perspectiva de gestores, trabalhadores e usuários. Pesquisar não o CECO, mas sua produção indica que ao lado das formas e dos objetos com seus contornos estáveis, existe um plano coletivo de forças que os produzem, um plano movente da realidade das coisas que não pode ser abandonado quando se pretende compreender um objeto. A cartografia aqui é apontada como estratégia de acesso, de análise e de construção desse plano.

De acordo com Deleuze e Guattari ${ }^{4}$, a Cartografia é útil para descrever processos mais do que estados de coisa. Isso nos indica um procedimento de análise a partir do qual a realidade a ser estudada está em constante transformação e movimento, uma realidade composta por diferentes narrativas, contextos e linhas de força a serem consideradas em sua complexidade e singularidade.

\section{METODOLOGIA}

$\mathrm{O}$ estudo caracteriza-se como uma pesquisa qualitativa, com caráter participativo, partindo do método da cartografia para a produção e análise de dados, conforme proposto por Passos, Kastrup e Escóssia ${ }^{5}$, bem como por Ferigato e Carvalho ${ }^{6}$.

O projeto da pesquisa foi aprovado pelo Comitê de Ética da Faculdade de Ciências Médicas da Unicamp, da Secretaria Municipal de Saúde de Campinas e SISNEP com o código 1036/2010.

Campinas foi o cenário de pesquisa, por fatores de conveniência e por ser a cidade com a maior concentração de CECOs por habitantes em todo o país. Nesse município foram campo de pesquisa 10 Centros de Convivência, a totalidade dos CECOs implementados na cidade na ocasião da pesquisa (março de 2011 a fevereiro de 2013). A maior parte desses CECOs estavam sob gestão da secretaria Municipal de Saúde, no entanto, haviam também alguns deles vinculados à Cultura e iniciativas comunitárias.
A produção de dados incluiu extensa pesquisa de campo, que se dividiu em etapas, com diferentes técnicas de produção de dados: (1) Pesquisa documental em registros oficiais dos Centros de Convivência da Prefeitura Municipal de Campinas; (2) habitação do território da pesquisa ${ }^{7}$, totalizando 400 horas de imersão no campo, registradas em diários de campo $^{8}$ nas quais se realizou observação participante em todos os CECOs (40 h/ serviço); (3) Convite aos participantes da pesquisa realizado por meio de apresentação da proposta no Fórum de Centro de Convivências do município e carta-convite formal aos gestores (4) Realização de 3 grupos focais semiestruturados ${ }^{9,10}$ respectivamente com os gestores, trabalhadores e usuários dos CECOs. Cada grupo, contou com um representante de cada CECO. Esses grupos foram áudio-gravados e transcritos; (5) Produção de registros fotográficos e vídeos; (5) Realização de oficina para socialização dos resultados da pesquisa aberta à rede de profissionais, usuários e gestores de CECOs; (6) Redação final da tese, cruzando narrativas de usuários (em itálico e espaçamento simples), com textos autorais e referências bibliográficas, a partir da técnica de interpolação de olhares ${ }^{11}$.

Essa interpolação, na fase de análise, nos ajudou a identificar a constante presença do termo "produção de encontros", como uma expressão fortemente utilizada pelos participantes da pesquisa, seja nos diários de campo ou nos grupos focais. Essa foi a primeira pista que o campo nos forneceu e que foi a linha norteadora da seguinte etapa da pesquisa: a cartografia dos encontros produzidos. Os materiais foram todos revisitados, e a partir deles identificamos diferentes planos da produção de encontros, que buscaremos apresentar nesse artigo.

A partir de Spinoza ${ }^{12}$ podemos identificar que a natureza dos encontros não é por si só positiva, nem negativa. $\mathrm{O}$ encontro entre os corpos se dão por conveniência ou desconveniência. O que se coloca no centro de interesse é o seu componente relacional, que pode ser aumentativo ou diminutivo da potência das partes que se relacionam, compondo-as ou decompondo-as. Para este filósofo, os encontros são essencialmente ético-afetivos, vinculados à noção de composição ou de decomposição na relação entre os corpos, na imanência da própria experiência. Um bom encontro é caracterizado pela composição, pelo aumento da potência de um corpo e um mau encontro é caracterizado pela decomposição ou diminuição da potência de agir ou da força de existir de um corpo.

A transformação que um encontro pode gerar num corpo é indeterminada, "não sabemos o que pode um corpo"12, mas sabemos que, o que ele pode ou não está 
Ferigato SH, et al. Cartografia dos Centros de Convivência. Rev Ter Ocup Univ São Paulo. 2016 jan./abr.;27(1):12-20.

diretamente relacionado com sua capacidade de afetar e ser afetado pelos encontros que ele experimenta. E nos CECOs? Que encontros contribuem para a construção da rede de saúde? Que afetos e práticas esses encontros produzem?

\section{RESULTADOS E DISCUSSÃO: OS ENCONTROS PRODUZIDOS NOS CECOS}

Ao analisar o material produzido durante a pesquisa, identificamos, pelo menos 4 planos: $O$ encontro entre pessoas, o encontro entre diferentes setores, o encontro com as atividades, o encontro com a cidade. Esses encontros propiciam um conjunto de desdobramentos que procuraremos abordar a seguir.

\section{$O$ encontro entre pessoas}

Ali é um espaço de encontro entre as pessoas que às vezes se cruzam na rua e nunca tinham de fato se encontrado (trabalhador 08 em grupo focal - T08GF).

Esse encontro também apresenta facetas singulares e distintas, incluindo encontros variados, entre eles: encontros entre profissionais, entre usuários, e entre profissionais e usuários.

Os encontros entre profissionais: a criação de redes, a transdisciplinaridade e o saber comunitário

$\mathrm{O}$ encontro entre profissionais identificado no processo da pesquisa produz, entre outras coisas, a transdisciplinaridade e a construção de redes de cuidado; isso por que, no contexto dos CECOS de Campinas, as equipes são compostas por profissionais contratados para o CECO, profissionais parceiros vindos de diferentes serviços, estagiários e voluntários; todos eles com diferentes formações. Os saberes advindos de diferentes núcleos profissionais e de diferentes pontos da rede de serviços têm sua atualização compartilhada e dá luz à potência do CECO como um dispositivo produtor e operador de redes. Referimo-nos às redes como redes de vida,

estruturas espaciais tendo sua existência guiada pelo número de conexões que contém. Um espaço conectado, constituído por uma rede móvel de pessoas e tecnologias nômades que operam em espaços físicos não contínuos. Assim, para integrar esses espaços, um nó (um serviço ou um indivíduo) não precisa compartilhar o mesmo espaço com os outros nós da rede móvel. O espaço híbrido é composto pela implicação de lugares diferentes e descontínuos ${ }^{13}$.
Lá, encontram-se profissionais e usuários de diferentes serviços de saúde, de outros setores como a Assistência Social e a Educação. Assim se produz rede em ato, a partir da dimensão relacional entre as pessoas.

A gente conseguiu firmar essa parceria com os Caps. Nessa coisa de gente poder afinar as relações e eu acho que o CECO entra com parceria, tanto no sentido de voluntários, quanto pessoas da rede que vem compor com a gente. Então, a gente tinha uma psicóloga do CS que vinha fazer uma oficina lá e ai para gente inclusive conseguir fazer essa rede não só de trabalhador, mas poder puxar a comunidade junto. (T05GF)

Em situações como essa, é o caráter relacional do trabalho nos CECOs que se mostra como terreno fértil para uma interação criadora e aprendizado mútuo. É na tensão entre a força do trabalho vivo e a forças que o querem capturar que se conformarão os profissionais e seus papéis ${ }^{14}$.

Em um dos CECOs, registramos a existência de uma oficina de teatro coordenada por um profissional da saúde e um ator. Neste encontro, era evidente a preocupação por parte dos profissionais em se contrapor ao uso ortodoxo da arte como pedagogia moral ou terapia em si mesmo, ao mesmo tempo, os profissionais da saúde também se preocupavam em se diferenciar do uso simplista da arte como mero instrumento de tranquilização ou entretenimento. Foi identificado um movimento de afirmação da vida por meio da atividade artística, dirigida por um artista e um profissional da saúde ${ }^{15}$.

Ali, se davam também o encontro com pessoas dotadas de saberes não encarnados em disciplinas, como os voluntários, que são, na maior parte das vezes, a expressão do saber comunitário, das singularidades do território (capoeiristas, costureiras, grafiteiros, etc.). $\mathrm{O}$ que se encontram desse modo, mais do que operadores de diferentes práticas são pessoas construtoras de redes sociais e subjetivas.

\section{Encontro de usuários: a afirmação das diferenças $e$ a criação de redes afetivas}

Pode entrar só pobre? Não, não pode entrar só pobre, por que a gente tem uma ética de que a todos cabem esse espaço, pobre, rico, preto, branco. Quem precisar dele, que venha (gestor 08 em grupo focal - G08GF).

Nos CECOs, encontram-se pessoas diferentes quanto à faixa etária, quanto à classe social, quanto ao 
gênero, quanto à presença ou não de alguma morbidade; pessoas com diferentes limitações e diferentes possibilidades. Essa heterogeneidade ocupa os mesmos grupos de atividade, com objetivos compartilhados, sendo uma marca importante dos CECOs.

Isso nos mobiliza a pensar com eles em grupos diversificados. Pessoas que estão em uso de drogas, idosas que querem fazer fuxico... o momento desse encontro é muito potente para construção de novas formas de viver a vida... eu não preciso viver só na droga, ou eu não preciso viver só no fuxico. E isso é promoção da vida. Isso desvia um pouco do jeito de fazer das UBS, dos Caps... é um outro momento. (T01GF)

Não se trata apenas do encontro entre pessoas diferentes, mas do cruzamento de modos heterogêneos de subjetivação ${ }^{16}$.

Agora estamos recebendo além dos adultos, crianças adolescentes; por que antes era mais o pessoal do Cândido Ferreira ${ }^{(1)}$. Isso é muito importante, não temos mais a marca do "sanatório" e sim de Centro de Convivência (T08GF).

O encontro entre essas diferenças, incomoda, transforma, põem em relação pessoas que possivelmente não se relacionariam em outras circunstâncias. Esses encontros são, na maioria das vezes alegres e surpreendentes, mas podem ser muito difíceis. De acordo com a narrativa de usuários e profissionais, o encontro com "a loucura" continua sendo o mais difícil a ser trabalhado pelos profissionais e para a comunidade considerada "não louca".

Um desafio é trazer a população para a convivência com o usuário de saúde mental (...) ainda somos pouco acessados (G03GF).

Por outro lado, usuários de serviços de saúde mental manifestam a importância desse dispositivo em suas vidas.

Quando eu era mais novo, meus filhos não queriam me visitar no hospital nem no CAPS, eles só foram pela primeira vez quando eles tinham 12 e 13 anos. Eu tenho uma foto deles dessa época e eles estavam grudados no meu braço, com medo de estar dentro de um hospital psiquiátrico, que era muito triste. Quando eu falei: Vai lá no CECO Espaço das Vilas, eles falaram: "Ah bom! Lá, nós vamos, no CECO a gente vai sim”. Foi ai que eles começaram a participar do meu tratamento. (Usuário 3 em grupo focal-U03GF)

Emerge daí parte importante dos processos de cuidado que ocorre nos CECOS, onde os profissionais cumprem a missão de intermediar os encontros, e cuidar para que, possíveis dificuldades decorrentes desse processo sejam trabalhadas.

\section{$O$ encontro entre profissional e o usuário: a transversalidade e novas relações de saber-poder}

$\mathrm{O}$ encontro entre profissionais e usuários, se configura como uma relação de poder, hegemonicamente vertical, na qual o profissional, detentor do saber age sobre o corpo do usuário, que assume o lugar objetal e passivo de intervenções. Observa-se que nos CECOs, muitas vezes, o encontro entre profissionais e usuários se dá a partir de maior transversalidade do poder. Para Guattari $^{17}$ a transversalidade é uma dimensão que pretende superar o impasse de uma verticalidade pura ou de uma simples horizontalidade. A transversalidade se realiza quando ocorre uma comunicação efetiva entre diferentes em diferentes sentidos. É importante salientar que, processos de transversalização como esse, são movimentos também idealizados e produzidos pela rede de atenção psicossocial a partir do advento da Reforma Psiquiátrica, e nesse sentido, não é um atributo exclusivo dos CECOs.

Nas observações de campo, isso acontecia especialmente quando, por parte dos profissionais se expressava a abertura em "operar a disponibilidade para o encontro, para propiciar o exercício de liberdade, promover contextos dialógicos, acompanhar os usuários na vida cotidiana, e mediar interações" (p.148) ${ }^{18}$.

Em momentos como esse, o corpo-profissional e o corpo-usuário, são convidados a experimentar novas possibilidades existenciais, novos dispositivos de subjetivação ${ }^{16}$. Usuários e profissionais são convidados a deslocar-se dos seus lugares tradicionais. Esse deslocamento de papéis identitários promove em ambos uma desestabilização permitindo que as relações de

(1) Referência ao Serviço de Saúde Dr. Cândido Ferreira - uma entidade beneficente, associação civil de direito privado, sem fins lucrativos, dedicada à parte significativa das atividades psicossociais no campo da saúde mental do município de Campinas. 
poder instituídas também se desestabilizem, atualizando outras formas-subjetividade.Para os usuários, apresentase a possibilidade de borrar a identidade historicamente produzida de 'doentes mentais' ou de 'cegos' ou 'diabéticos' para dar passagem a novos devires: artesãos, artistas, dançarinos, grafiteiros, pintoras.

Nas oficinas deslocam-se também os saberespoderes. Diferentemente da sala de atendimento ou das salas de aula tradicionais, em que o profissional "detém o saber" sobre a vida ou o processo de aprendizagem do outro, numa oficina de música, pode haver um usuário que domina um número maior de instrumentos musicais do que o coordenador do grupo.

Eu mesma não sabia fazer mosaico e hoje eu coordeno uma oficina de mosaico com 15 pessoas. Me sinto feliz por isso, a gente tem a oportunidade de partir de um território que é aberto (T08GF).

Neste sentido, as intervenções produzidas nos CECOs não podem se realizar efetivamente, se os próprios profissionais não experimentarem, mais autonomia e algum grau de ruptura com seus saberes disciplinares. Isso implica tomar a intervenção não apenas como especialidade profissional que se oferta aos usuários e seus familiares, mas como trabalho a ser construído e gerido no encontro ${ }^{14}$.

Além disso, nesses espaços, o olhar do profissional para a potencialidade do usuário não é secundário, mas é o fio condutor desse encontro, uma postura ética que parte do reconhecimento do outro como legítimo outro, do reconhecimento de cada um como insuficiente, e o reconhecimento de que o sentido de uma situação é produzido pelo conjunto de saberes presentes ${ }^{19}$.

A potencialidade é você ouvir o usuário dizer das expectativas dele e do que ele tem conquistado a partir da experiência com o CECO, você conseguir tratar da doença olhando a partir da saúde, colocar acima de qualquer coisa as potencialidades, os desejos dos usuários (T05GF).

No entanto, esse olhar, vem de diferentes setores, e assim, esse encontro poderá ou não produzir efeitos terapêuticos, liberando o profissional da saúde desse mandato e o profissional de outros setores dessa encomenda:

O encontro pode também não produzir uma terapêutica, porque a gente não tem a necessidade de estar nesse lugar o tempo todo... (G06GF).
Nesse encontro, esses corpos podem produzir novas superfícies de contato para além da superfície-tratamento, produzir efeitos a um só tempo individuais e coletivos, advindos de uma intervenção que visa em última instância incluir ou re-colocar o sujeito no plano de produção coletivo. Nesse plano, nos permitimos encontrar o que não procurávamos ou ser encontrado pelo acontecimento ${ }^{7}$.

\section{Encontro entre pessoas com a atividade: a linguagem da ação e a construção de novas subjetividades}

A maior parte dos encontros estabelecidos nos CECOs se dão intermediados por oficinas de atividades (artesanais, artísticas, agrícolas, culinárias, esportivas, educativas, socioculturais, de geração de renda...). Para Galletti ${ }^{3}$, as oficinas funcionam mais como vetores produtores de existência do que produtores de intervenção clínica.

Esses espaços não atendem a modelos rígidos, possuem caráter experimental e podem promover a desestabilização nos enquadrinhamentos específicos de cada área. Por seu caráter transdisciplinar e de experimentações múltiplas $^{3}$, comumente incorpora a entrada de um terceiro elemento no encontro entre trabalhador e usuário: a atividade.

Para Castro e Lima et al. ${ }^{20}$ as atividades humanas são constituídas por um conjunto de ações que apresentam qualidades, demandas capacidades, materialidade e estabelecem mecanismos internos para sua realização. A linguagem da ação é um dos muitos modos de conhecer a si mesmo, o outro, o mundo, o espaço e o tempo em que vivemos e a nossa cultura.

Não se trata apenas do confronto com uma nova matéria de expressão, mas a constituição de complexos de subjetivação. Indivíduo-grupo-atividade- trocas múltiplas que oferecem diversificadas formas de composição de uma corporeidade existencial ${ }^{16}$.

Quando interrogados sobre como souberam dos CECOS e por que frequentam esse espaço, muitos a maior parte dos usuários fazem referência a atividades específicas:

Soube pelo meu vizinho que tinha oficina de culinária e vim participar ou eu frequento o CECO por que adoro pintar, quando estou pintando me sinto mais leve (Relato de usuários registrado em diário de campo - UDC).

Discursos como esse, remetem à possibilidade de encontros intermediados por ações que são produtoras de sentido para o sujeito. Para Galletti ${ }^{3}$ trata-se de "fazer algo", que seja repleto de sentido para os usuários. 
No relato dos usuários, o encontro com a atividade esteve relacionado (a) à seu fator terapêutico, (b) à sua função de ocupação do tempo e espaço (c) à função de transformação de si e de suas vidas.

Pelo menos para mim, o esporte foi fundamental como terapia (...), por que às vezes a atividade vai muito além do que a gente imagina. (U01GF).

Quando acabou a escola eu fiquei no sedentarismo de casa, por que os cursos e escolas para cegos diziam que eu já tinha aprendido tudo que eles tinham para oferecer, $e$ o mundo dos que enxergam me dizia que não tinha espaço para mim... Até que veio o CECO e eu voltei a viver, a ter ocupação e ter para onde ir quando eu saio de casa (UDC).

Em outras narrativas, a atividade aparece como um canal produtor de mudança da percepção que o outro tem de si, uma possibilidade para diminuir estigmas, produzir direitos e gerar novos encontros entre o sujeito e seu socius ${ }^{20}$ :

Às vezes a pessoa sai para ir no CAPS e as pessoas pensam: "aquela pessoa tem um distúrbio, ele é mental, ele vai no psiquiatra...”, quando essa pessoa começa a fazer uma atividade no CECO, as próprias pessoas do bairro, já começam a olhar a gente com outros olhos, por que ele vê que a gente é capaz de alguma coisa legal (U04GF).

As oficinas de atividades, neste contexto, possibilitam cada um ser reconhecido e se reconhecer por outros fazeres ${ }^{20}$. Ali diferentes singularidades podiam inscrever-se no mundo a partir da participação em atividades que tinham lugar na cultura, construindo novos territórios existenciais.

Para Guattari ${ }^{16}$ a finalidade última da atividade humana é a produção de uma subjetividade que enriqueça de modo contínuo sua relação com o mundo. Assim, o que se produzia objetivamente numa oficina era o resultado de um constante transitar entre o ritmo singular de cada um e a coletivização dessas singularidades. "Trata-se de ampliar a vida, buscar interlocuções, favorecer encontros, possibilitar trânsitos novos" $(\mathrm{p} .57)^{20}$.

\section{O Encontro entre diferentes setores e a produção de práticas intersetoriais}

A intersetorialidade pode ser entendida como a articulação de saberes e experiências no planejamento, na realização ou na avaliação de ações, com o objetivo de alcançar resultados integrados em situações complexas, visando a um efeito sinérgico no desenvolvimento social ${ }^{21}$.
Foi identificado, no campo pesquisado, que 5 Setores estão presentes direta ou indiretamente no cotidiano dos CECOs: Saúde, Educação, Assistência Social, Esportes e Cultura.

Diversas atividades se mostram como meio para a operacionalização de ações intersetoriais: cursos de informática e as aulas de alfabetização para adultos; diferentes modalidades esportivas, oficinas de música, teatro, dança, etc.

A identificação dos CECOs pela comunidade como um espaço cultural, facilita e estimula a vinculação de pessoas com as mais diferentes limitações, que precisavam de espaços de encontro para além do que pode oferecer o setor isoladamente. Idosos, deficientes físicos e sensoriais, pessoas com transtornos mentais, crianças em situação de vulnerabilidade são apenas alguns desses exemplos.

$\mathrm{O}$ encontro entre diferentes setores amplia a abordagem do setor saúde que inicialmente foi o setor responsável pela implementação dos CECOs em Campinas. Ali, assistimos brotarem redes alternativas que derivam da própria rede hegemônica e se conectam com outras redes, com a cidade, com a comunidade e com outros modos de pensar a saúde ${ }^{22}$.

As ações intersetoriais acontecem por que a gente entende que produzir lazer é uma forma de produzir saúde, assim como cultura, educação também produzem saúde. (G03GF)

Infelizmente, as alianças e parcerias que são realizadas no cotidiano micropolítico dos CECOs, nem sempre se viabilizam do ponto de vista das Secretarias Municipais e da macropolítica. Isso gera sobreposição de ações e uma cisão entre o modelo de atenção proposto e os modelos de gestão e financiamento.

A gente quer montar um CECO, mas já tem um no território (que é da assistência social). Em vez das secretarias se juntarem e potencializar cada um constrói sua casinha própria e está na hora de juntar o que se faz em duas casas numa casa só, (...) Pensar essas outras secretarias juntas pra construção das diretrizes do CECO seria uma coisa interessante, por que hoje, na gestão central não tem intersetorialidade (G08GF).

Por fim, no encontro entre diferentes setores, se afirma mais uma vez a potência do CECO na ocupação da zona de fronteira. Fronteira entre as disciplinas e seus campos de saber. A intersetorialidade presente nos CECOs se dava a partir de trocas ritmadas, a rede se produzia 
Ferigato SH, et al. Cartografia dos Centros de Convivência. Rev Ter Ocup Univ São Paulo. 2016 jan./abr.;27(1):12-20.

por letras de música, por instrumentos e profissionais compartilhados entre diferentes pontos de atenção, pela participação conjunta em apresentações e não apenas por papéis ou pactos de gestão.

\section{O encontro com a cidade e com o território: a reinvenção dos espaços públicos e a criação de zonas de comunidade}

Outro encontro importante de ser registrado quando pensamos o CECO é o encontro entre os usuários dos CECO e a cidade.

Eu fico pensando que não é só promover encontro com o outro, mas também com o meio social, [...] Tem um querer nosso, que é cutucar as pessoas para descobrirem seu território e sua cidade, pra se repensar os espaços de lazer e de socialização que a gente ocupa... (G08GF)

A cidade é tomada como importante espaço de investimento das Políticas Públicas. Pensamos a cidade também como "cidade subjetiva" 23 e o "Território" antes de tudo como um lugar de passagem, envolvendo aspectos biológicos, geográficos, subjetivos e sociológicos, entre outros.

O território pode ser relativo tanto a um espaço vivido, quanto a um sistema percebido no seio da qual um sujeito se sente "em casa". O território é sinônimo de apropriação, de subjetivação fechada sobre si mesma. Ele é o conjunto de projetos e representações nos quais vai desembocar, pragmaticamente, toda uma série de comportamentos, de investimentos, nos tempos e nos espaços sociais, culturais, estéticos, cognitivos (p.323) ${ }^{24}$.

Se os territórios cumprem uma função de delimitação, apropriação e articulação, em uma cidade, é possível criar conexões e ações de pertencimento a certo território e ao mesmo tempo movimentos para reinventálo, transformá-lo.

Para Souza e Tedesco ${ }^{25}$ a vida no território amplia conexões e, com isso, aumenta a potência do viver. Pessoas que antes viviam marginalizadas passam a cooperar entre si à medida que são inseridos em redes afetivas ${ }^{19}$. Este aumento de potência ocorre por conexões que ampliam os territórios cooperativos numa produção de território comum $^{26}$.

O Centro de Convivência, como espaço público de convívio pode apresentar-se como dispositivo importante para a ressignificação do encontro entre pessoas e a cidade, para uma possível recriação da forma como os cidadãos ocupam os espaços públicos, se apropriando dele, numa postura ativa na sua construção.

Frisamos o termo "postura ativa", por identificar na fala de diferentes usuários uma mudança dos modos em que essa pessoa habita a cidade a partir do encontro com os CECOs, uma mudança que aparentemente, retira o sujeito de um lugar passivo, marginalizado, para um lugar de maior potencial protagônico, um lugar que amplia seu agir, que amplia a cidade.

O pessoal de idade, que está aposentado já se sentia "fora de época", e nessas oficinas, nessa convivência entre idosos com jovens e crianças, me ajudou muito. Ainda tem lugar para mim nessa época. As pessoas se sentem mais amparadas. (U02GF)

No CECO a gente pega o ônibus e vai para lá, se tem um ensaio da orquestra sinfônica, eu vou assistir e é de graça. (U03GF)

Nessa direção, não são apenas os usuários que se modificam, mas a cidade e as pessoas que a ela pertencem também:

Nossa festa junina também não foi dentro do serviço, mas na quadra de esportes do bairro. De repente as pessoas que estavam na praça também estavam lá junto. (T05GF)

O CECO foi construido do lado de uma boca de fumo, $e$ com o tempo e não só a boca de fumo tem transformação, mas o modo como eles passam a se apropriar daquele espaço, a composição com as lideranças religiosas, o pastor, o padre, sei lá mais quem, que também está lá dentro. (T06GF).

Alguns CECOs, localizados em praças públicas trazem essa relação entre as pessoas e o espaço público de modo bastante singular. Visualizamos a diferença na praça e a praça das diferenças. A praça como arena e palco para ações políticas, artísticas, efêmeras e radicais. A convivência proposta extrapola as paredes do CECO, e o sujeito que procurou o CECO, encontra a praça.

Assim, os efeitos de enfrentamento à exclusão observados nos CECOs, vão além do movimento da inclusão de grupos tradicionalmente marginalizados funcionando como um espaço de encontro para pessoas que sentiam-se excluídos, especialmente em tempos neoliberais, que produz novas formas de exclusão. 
Eu não sou doente mental, não tenho nenhuma doença grave, nem sou tão velha, mas tinha alguma coisa que faltava, me sentia muito sozinha desde que meus filhos se casaram. Ia para o parque Taquaral todo dia, mas as pessoas andam, andam por lá e você não consegue conhecer ninguém. Quando eu conheci aqui, vi que era uma convivência de um jeito diferente, onde a gente podia conhecer as pessoas, mesmo aquelas que antes a gente tinha medo, é divertido, a gente cresce. Não me sinto mais sozinha" (UDC).

\section{CONSIDERAÇÕES FINAIS}

Neste trabalho cartografamos a produção dos CECOs, tendo como campo de investigação o município de Campinas, buscando apresentar estratégias de convivência que podem ser úteis para o desenvolvimento de ações semelhantes em outras localidades.

Num primeiro mergulho em campo, identificamos "a produção de encontros" como a principal produção dos CECOs. Com base da teoria spinozana, passamos então a analisar alguns dos encontros que os CECOs produzem, sistematizando esses encontros em alguns planos: encontro entre pessoas, entre saberes, entre setores, encontro com atividades e com a cidade.

Esses encontros, além de dar visibilidade às práticas e saberes que constituem os CECOs, também

\section{REFERÊNCIAS}

1. Ferigato SH. Cartografia dos Centros de Convivência de Campinas: produzindo redes de encontros [Tese]. Campinas: Departamento de Saúde Coletiva, Unicamp; 2013. Disponível em: http://www.bibliotecadigital. unicamp.br/document/?code $=000906645$.

2. Brasil. Ministério da Saúde. Secretaria de Atenção à Saúde. DAPE. Coordenação Geral de Saúde Mental. Reforma psiquiátrica e política de saúde mental no Brasil. Documento apresentado à Conferência Regional de Reforma dos Serviços de Saúde Mental: 15 anos depois de Caracas. Brasília: OPAS; 2005. Disponível em: http://bvsms.saude. gov.br/bvs/publicacoes/Relatorio15_anos_Caracas.pdf.

3. Galletti MC. Oficina em saúde mental: instrumento terapêutico ou intercessor clínico? Goiânia: Editora UCG; 2004. nos dão pistas importantes sobre que tipo de políticas, estratégias de intervenção e de produção de redes que os CECOs podem produzir. Ou seja, a produção de encontros não se encerra em si mesma, desencadeando um conjunto de outras produções técnicas, socioculturais, afetivas e políticas, que buscamos destacar nas discussões de cada resultado apresentado.

Realizando uma análise transversal sobre esses encontros, identificamos que os CECOs são dispositivos potentes para a promoção de políticas intersetoriais, para a intervenção na cidade (produzindo zonas de comunidade e criando novos modos de circulação pelos territórios), para a criação de laços sociais e para a contraposição à práticas estigmatizantes e excludentes. O CECO, em sua constituição "encarna" a rede nele próprio, numa implicação de pessoas e lugares singulares.

A partir da perspectiva da produção de encontros, podemos dizer que os CECOs, podem funcionar na rede de saúde e na rede intersetorial como um dispositivo ativador de experiência ou como um motor de experimentação.

Embora essas experimentações vividas nesses locais e a prática de diversos municípios como Campinas, constatem sua relevância, os investimentos acadêmicos e político-econômicos nestes dispositivos mostram-se ainda insuficientes do ponto de vista nacional e merecem ser mais bem explorados, principalmente no que tange à construção das Políticas Públicas intersetoriais no Brasil.

4. Deleuze G. Guattari F. Mil Platôs: capitalismo e esquizofrenia. São Paulo: Ed 34; 1995.

5. Passos E, Kastrup V, Escóssia L, organizadores. Pistas do método da cartografia: pesquisa-intervenção e produção de subjetividade. Porto Alegre: Sulina; 2009.

6. Ferigato S, Carvalho S. A cartografia como método de pesquisa qualitativa em saúde: desafios para o devir-pesquisador. Interface Comunic Saúde Educ. 2011;15(38):663-75. Disponível em: http://www.scielo.br/ pdf/icse/v15n38/aop3411.pdf.

7. Alvarez J, Passos E. Cartografar é habitar um território existencial. In: Passos E, Kastrup V, Escóssia L, organizadores. Pistas do método da cartografia: pesquisaintervenção e produção de subjetividade. Porto Alegre: Sulina; 2009. p.131-49. 
Ferigato SH, et al. Cartografia dos Centros de Convivência. Rev Ter Ocup Univ São Paulo. 2016 jan./abr.;27(1):12-20.

8. Lourau R. Implicação e sobreimplicação. In: Altoé S, organizador. René Lourau: analista institucional em tempo integral. São Paulo: Hucitec; 2004. p.186-98.

9. Onocko Campos RT, Furtado JP, Passos E, Benevides $\mathrm{R}$, organizadores. Pesquisa avaliativa em saúde mental: desenho participativo e efeitos da narratividade. São Paulo: Hucitec; 2008.

10. Fontana A, Frei JH. The interviw: from neutral stance to political Involvment. In: Denzin NK, Lincoln S. Handbook of qualitative reserch. 3a ed. Thousand Oaks, California: Sage Publications; 2005. p.59-70.

11. Azevedo BM. O ensino da gestão no curso de graduação de medicina da FCM/UNICAMP: possíveis encontros entre universidade e serviços de saúde [Dissertação]. Campinas: Departamento de Saúde Coletiva, Unicamp; 2011. Disponível em: http://www.bibliotecadigital.unicamp.br/ document $/$ ?code $=000863412$.

12. Spinoza B. Ética. Trad. Tomaz Tadeu. 2a ed. Belo horizonte: Autêntica editora; 2008.

13. Souza E, Silva A. Arte e tecnologias móveis: hibridizando espaços públicos. In: Parente A, organizador. Tramas da rede. Porto Alegre: Sulina; 2004. p.282-97.

14. Barros RB. Reforma psiquiátrica brasileira: resistencias e capturas em tempos neoliberais. In: Conselho Federal de Psicologia, organizador. Loucura, ética e política: escritos militantes. São Paulo: Casa do Psicólogo; 2003. p.196-206.

15. Ferigato S, Sy A, Carvalho SR. Explorando las fronteras entre la clínica y el arte: relato de una experiencia junto al Frente de Artistas del Borda. Salud Colectiva (Lanus). 2011;7(3):347-63. Disponível em: http://www.scielo.org.ar/ scielo.php?pid=S1851-82652011000400005\&script $=$ sci arttext.

16. Guattari F. Caosmose: um novo paradigma estético. Trad. Ana Lúcia de Oliveira. São Paulo: Ed. 34; 2006.
17. Guattari F. Psicanálise e transversalidade: ensaios de análise institucional. Trad. Adail Ubirajara Sobral, Maria Stela Gonçalves. Aparecida: Idéias \& Letras; 2004. p.75-84. (Coleção Psicanálise Século I).

18. Nicácio F, Campos GWS. Afirmação e produção de liberdade: desafio para os centros de atenção psicossocial. Rev Ter Ocup Univ São Paulo. 2007;18(1):14351. doi: http://dx.doi.org/10.11606/issn.2238-6149. v18i3p143-151

19. Teixeira RR. As redes de trabalho afetivo e a contribuição da saúde para a emergência de uma outra concepção de público. Disponível em: http://www.corposem.org/rizoma/ redeafetiva.htm.

20. Castro ED, Lima EA, Brunello MIB. Atividades humanas e terapia ocupacional. In: De Carlo MMRP, Bartallotti CC, oragnizadores. Terapia ocupacional no Brasil: fundamentos e perspectivas. São Paulo: Plexus editora; 2001. p.41-59.

21. Junqueira LAP, Inojosa RM. Desenvolvimento social e intersetorialidade: a cidade solidária. São Paulo: FUNDAP; 1997.

22. Pelbart PP. Vida capital: ensaios de biopolítica. São Paulo: Iluminuras; 2003.

23. Guattari F. Espaço e poder: a criação de territórios na cidade. Espaço Debates (São Paulo). 1985;5(16):109-20.

24. Guattari F, Rolnick S. Micropolítica: cartografias do desejo. 4a ed. Petrópolis: Vozes; 1996.

25. Tedesco S, Souza TP. Territórios da clínica: redução de danos e os novos percursos éticos para a clínica das drogas In: Carvalho SR, Ferigato SH, Barros MEB. Conexões: saúde coletiva e políticas de subjetividade. São Paulo: Hucitec; 2009.

26. Negri A, Hardt M. Multidão. Rio de Janeiro: Record; 2005.

Artigo recebido em: 21.05.15

Artigo aceito em: 16.12 .15 